\title{
Kernos
}

Revue internationale et pluridisciplinaire de religion grecque antique

33 | 2020

Varia

\section{Gods and Mortals in Greek and Latin Poetry}

\section{Vinciane Pirenne-Delforge}

\section{(2) OpenEdition \\ Journals}

\section{Édition électronique}

URL : https://journals.openedition.org/kernos/3658

DOI : 10.4000/kernos.3658

ISSN : 2034-7871

\section{Éditeur}

Centre international d'étude de la religion grecque antique

\section{Édition imprimée}

Date de publication : 31 décembre 2020

Pagination : 352-353

ISBN : 978-2-87562-264-8

ISSN : 0776-3824

\section{Référence électronique}

Vinciane Pirenne-Delforge, «Gods and Mortals in Greek and Latin Poetry », Kernos [En ligne], 33 | 2020, mis en ligne le 31 décembre 2020, consulté le 06 décembre 2022. URL : http://

journals.openedition.org/kernos/3658; DOI : https://doi.org/10.4000/kernos.3658

Ce document a été généré automatiquement le 6 décembre 2022

Tous droits réservés 


\title{
Gods and Mortals in Greek and Latin Poetry
}

\author{
Vinciane Pirenne-Delforge
}

\section{RÉFÉRENCE}

Lucia ATHANASSAKI, Christopher NAPPA, Athanassios VeRGADos (éd.), Gods and Mortals in Greek and Latin Poetry. Studies in Honor of Jenny Strauss Clay, Rethymnon, School of Philosophy, University of Crete, 2018. 1 vol. 17,2 × 23,8 cm, 367 p. (Ariadne, suppl. 2). ISBN : 978-618-82229-2-2.

Ce bouquet d'articles est un cadeau offert à Jenny Strauss Clay par de « vieux amis » qui connaissent aussi bien son travail que sa personne. Les thèmes choisis pour honorer celle qui fut professeure à l'Université de Virginie à Charlottesville, créent un jeu de miroir avec les intérêts scientifiques qu'elle a déployés tout au long d'une riche carrière d'enseignante et de chercheuse : les dieux et les mortels, la poésie, qu'elle soit grecque ou latine. Au-delà de réflexions personnelles (la traduction d'un poème d'Horace par D. Arnson Svarlien, le «tribut à un mentor » de D. Mendelsohn ou l'évocation de la jubilaire par W.W. Briggs, suivie de sa bibliographie), ce sont ces trois ensembles, souvent entremêlés, qu'abordent les articles du volume ${ }^{1}$.

2 L'étude de Nancy Felson fait directement écho aux importants travaux de J.S. Clay sur la Théogonie d'Hésiode en interrogeant le rôle de Gaia dans le poème, en relation avec Zeus. "Faiseuse de rois", la déesse remplira finalement son rôle de "siège à jamais stable » avec l'aide du divin basileus pour qui elle a engendré un ultime opposant en la personne de Typhon. - Lucia Athanassaki interroge aussi la poésie chère à J.S. Clay, mais du côté de l'autorité chorale, cette fois, et de l'interaction rituelle entre hommes et dieux qu'elle met en scène, comme le thématisera également Platon qui en fait un outil essentiel de la paideia. - Zoe Stamatopoulou s'arrête quant à elle à la figure de Dikè chez Eschyle (fr. 281 Radt), qu'elle compare à ce qu'Hésiode en avait fait dans Les Travaux et les Jours : en l'occurrence, le poète tragique confère à la déesse d'agir selon sa 
propre puissance d'action et non seulement comme informatrice de Zeus. - David Kovacs se penche sur la figure d'Antigone chez Sophocle et sur ce qu'il considère comme une incohérence entre l'héroïne prête à mourir pour aller au bout de son combat et la jeune fille qui se lamente sur sa mort prématurée. Refusant tout recours à une quelconque figure de «martyre » à laquelle Antigone a pu être ramenée, il ancre son analyse dans une interprétation théologique "grecque » et voit dans le sort de la jeune femme la main des dieux qui l'instrumentalisent pour servir leur hostilité à l'égard des Labdacides. - A. Vergados analyse finement la figure d'Hermès "affamé " dans le Ploutos d'Aristophane en la chevillant au thème sous-jacent de la comédie, à savoir la fin de la charis, de la "réciprocité » normale entre hommes et dieux dans un monde où Ploutos, la "richesse", est désormais accessible à tous. - Th. Hubbard se tourne vers l'Hymne à Artémis de Callimaque pour y déceler comment la divinité joue du regard masculin, qu'il soit divin ou humain, notamment dans des récits où les jeunes filles de son chœur sont pourchassées par des hommes. - A. Mori s'attache pour sa part aux Idylles 6 et 11 de Théocrite, et à la figure du cyclope Polyphème sur le thème de l'aveuglement: celui du poète clairvoyant, d'une part, celui de Polyphème centré narcissiquement sur lui-même, de l'autre. - C'est également à Théocrite, dans l'Idylle 7, que s'intéresse B. Jasnow, et notamment au rôle de Déméter dans le poème, refermant ainsi la partie de l'ouvrage consacrée au monde grec. Six autres articles forment le matériau "latin» du volume qui s'ouvre ainsi à d'autres intérêts de J. Strauss Clay, entre Horace, Catulle, Properce, Ovide et, plus généralement, la poésie des débuts de l'Empire romain.

Comme tout volume d'hommage, celui-ci n'échappe pas au caractère quelque peu disparate d'un ensemble fondé sur les intérêts particuliers de ses auteurs. Toutefois, la volonté de se rattacher, d'une manière ou d'une autre, aux travaux de la figure tutélaire de J. Strauss Clay confère à cette guirlande festive une unité qui lui est propre: le goût pour la poésie antique et la volonté de comprendre les diverses manières dont les Grecs et les Romains y faisaient agir leurs dieux.

\section{NOTES}

1. La table des matières a été publiée dans Kernos 32 (2019), p. 369-370. 


\section{AUTEURS}

\section{VINCIANE PIRENNE-DELFORGE}

Collège de France

Université de Liège 